Volume: 1 | Volumen 1 | Número 1 | Number 1 | pp. $89-107$ ISSN: 2634-355X (Print) | ISSN: 2634-3568 (Online) journals.tplondon.com/yeiya

First Submitted: 5 September 2020 Accepted: 24 November 2020 TRANSNATIONAL PRESS ${ }^{\circledR}$ DOI: https://doi.org/10.33182/y.v1i1.1303

\title{
Extractivismos agropecuarios en tiempos de pandemia: flexibilizaciones, asimetrías, autoritarismos y otros efectos derrame
}

\author{
Tamara Artacker ${ }^{1}$, Jorge Campanini ${ }^{2}$ y Eduardo Gudynas ${ }^{3}$
}

\section{Resumen}

En el contexto de la pandemia por Covid19, los gobiernos de América del Sur han mantenido los extractivismos agropecuarios (agricolas, ganaderos y forestales). En unos casos se los presenta como solución a la caída de extractivismos en petróleo y minerales. En otros casos ocurren cambios entre distintos productos agropecuarios. Esta estrategia implica la persistencia de impactos sociales y ambientales, y acentuian las asimetrías entre actores empresariales y agricultores pequeños o campesinos. A pesar que en la crisis por la pandemia permitía promover una agricultura como proveedora de alimentos para atacar el componente nutricional entre los sectores más pobres, persistió la postura de concebirla como proveedora de mercancias de exportación, acentuándose los extractivismos. Se mantuvieron y en algunos casos se profundizaron los efectos derrame, tales como flexibilizaciones sociales, laborales y ambientales, y se fortalecieron políticas públicas que sostienen y blindan a los extractivismos.

Palabras clave: extractivismos; agricultura; ganadería; extractivismo agropecuario; efectos derrame

\section{Abstract \\ Agricultural extractivisms in times of pandemic: flexibilities, asymmetries, authoritarianisms and other spill-over effects}

In the context of the Covi19 pandemic, South American government sustained agricultural extractivisms (including agriculture, livestock and forestry). In some cases, they are presented as a solution to the reduction of oil and mineral extractivisms. In other cases, changes occur between different agricultural products. This strategy results in maintaining social and environmental impacts, and strengths asymmetries between business actors and small farmers or peasants. Despite the crisis due to the pandemic was an opportunity for those alternatives focused on supplying food to overcome the nutritional component among the poorest sectors, the prevailing strategy promotes an agriculture that supply merchandises for export, resulting in promoting extractivisms. The spill-over effects were maintained and in some cases deepened, such as social, labor and environmental flexibilities, and public policies that support and shield extractivism were strengthened.

Keywords: extractivisms; agriculture; livestrock; agricultural extractivism; spill over effects

\section{Introducción}

En los últimos años se han sumado múltiples estudios sobre los extractivismos en América Latina, sobre todo enfocados en los sectores minero y petrolero. Sin embargo, también son muy relevantes otras variedades de extractivismos, incluyendo aquellos asociados a la

\footnotetext{
${ }^{1}$ Instituto de Estudios Ecuatorianos. Quito, Ecuador. Correo electrónico: t.artacker@gmail.com

${ }^{2}$ Centro de Documentación e Información Bolivia. Cochabamba, Bolivia. Correo electrónico: campanini@hotmail.com

${ }^{3}$ Centro Latino Americano de Ecología Social (CLAES). Montevideo, Uruguay. Correo electrónico: egudynas@ambiental.net
} 
agricultura, ganadería, forestería y pesca. La importancia de todos estos tipos de apropiación de recursos naturales está no solamente en los impactos sociales y ambientales que generan, sino que además tienen múltiples consecuencias en el terreno del desarrollo, la cultura y la política.

La actual pandemia por Covid19 está afectando todo ese entramado. Por un lado, ante esta crisis los gobiernos redoblan su adhesión a los extractivismos con la esperanza de remontar las caídas económicas. Por otro lado, la crisis sanitaria hace que muchos otros temas, como el papel actual de los extractivismos, quede en segundo o tercer plano.

El propósito de este artículo es analizar algunas tendencias clave que bajo la pandemia se observan en los extractivismos agropecuarios (agrícola, ganadero y forestal), en los países de América del Sur (excepto Guyana y Surinam), entre enero y noviembre de 2020. Aunque nuestro aporte es evidentemente provisorio en tanto esa pandemia está en marcha, encontramos que se está reforzando ese tipo de apropiación de recursos naturales. Pero a la vez, la crisis que padecen los países hace más difícil enfrentar y debatir sobre sus impactos, y persisten sus efectos derrames en las políticas públicas.

\section{Definición y delimitación de los extractivismos agropecuarios}

Los extractivismos son aquí definidos como un tipo de apropiación de recursos naturales, entre varios, que se caracterizan por una remoción masiva, donde el $50 \%$ o más está destinado a la exportación, y que son comercializados como materias primas o commodities (estos y otros detalles de la definición se analizan en Gudynas, 2015).

Desde esta perspectiva existen múltiples tipos de extractivismos, incluyendo a los más conocidos basados en minerales o hidrocarburos. Pero lo mismo ocurre con distintos rubros agrícolas, ganaderos o forestales, como pueden ser los ejemplos de las exportaciones de banano, carne vacuna o pasta de celulosa. A diferencia de los sectores mineros o petroleros, en este caso la apropiación ocurre sobre recursos renovables. Por lo tanto, en estos extractivismos los productos son "cosechados", como pueden ser granos o carnes. De todos modos, la base ecológica sobre la que se practica esta apropiación tiene límites tales como la calidad de los suelos o el acceso al agua de riego.

El entendimiento de los extractivismos como un tipo de apropiación de recursos naturales permite, a su vez, diferenciarlo de otros tipos como pueden ser aquellos propios de la agricultura campesina, como es común en las regiones andinas, o de pequeños y medianos agricultores, como se observa en los países del Cono Sur. Por lo tanto, no todas las actividades agropecuarias están asociadas a los extractivismos sino únicamente aquellas que están organizadas hacia la exportación. No debe confundirse a un campesino con un empresario agroexportador.

También debe tenerse presente que la definición de extractivismo no está determinada por la propiedad de la tierra, por el acceso a ella, o por el tipo de actores u organización económica que cosechan los recursos naturales. Entonces, pueden existir extractivismos agropecuarios basados en el latifundio, pero también es posible que miles de pequeños propietarios participen de esa actividad como ocurre con la soya en el Cono Sur. Esta es una situación análoga a la minería de oro que puede estar en manos de grandes corporaciones, o en miles de personas como se observa con el oro aluvial, aunque de todos modos el recurso apropiado se inserta en cadenas de exportación.

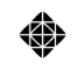

Yeiyá 
Los extractivismos agropecuarios tienen una enorme importancia. En el total estimado de 135 millones toneladas métricas de recursos naturales exportados desde América Latina en 2016, un $30 \%$ corresponde a biomasa (implicando más de 300 millones ton $\mathrm{m}$ ), lo que supera a las exportaciones de combustibles fósiles (Infante-Amate et al., 2020). Los más altos exportadores netos de biomasa en el continente son Argentina, Paraguay y Uruguay. A diferencia de los extractivismos mineros y petroleros, los agropecuarios involucran enclaves extendidos, como son las áreas de monocultivos. El resultado de esto son modificaciones y alteraciones en grandes escalas geográficas. A su vez, requieren de distintas áreas de soporte, en especial obras de regadío, y de redes de interconexión que permitan la entrada de insumos (como pueden ser agroquímicos, semillas, maquinaria de siembra y cosecha) como la salida de lo cosechado (granos, ganado, etc.).

Esto se puede ilustrar con la evolución de la ecoregión del Cerrado, donde las áreas naturales son transformadas en predios ganaderos o agrícolas. Se estima que entre el 50\% a $60 \%$ de la superficie de la ecoregión ha sido transformada (lo que implica al menos 1 millón de km2) (véase, por ejemplo, Grecchi et al., 2014). Asimismo, la soya brinda otro ejemplo ya que, por ejemplo, en los países del Cono Sur, afectan más de 61 millones hectáreas. Ese tipo de extractivismo tiene todo tipo de impactos sociales, territoriales y ambientales, desde deforestación y pérdida de biodiversidad, a la repetida contaminación por agroquímicos se suelos y aguas, entre otros (resumidos en Gudynas, 2015).

Los estudios sobre los extractivismos agropecuarios son más recientes que los enfocados en minerales o hidrocarburos (Gudynas, 2010). De todos modos se están sumando muchos aportes, tanto en conceptos como en estudios de caso. Entre ellos se pueden señalar el detallado estudio en Bolivia por McKay (2018), las precisiones de Reboratti (2017) en Argentina, Fernandes (2019) sobre la captura de tierras para el agroextractivismo en Brasil, Ojeda y Berman-Arévalo (2020) sobre la violencia en los extractivismos agrarios en Colombia, o la idea de un capitalismo agroextractivo de Alonso-Fradejas (2019).

\section{Situación de los mercados y demanda global}

Los extractivismos expresan una condición glocal. Por un lado, están asentado en sitios desde donde se extraen los recursos naturales, y que para el caso de la agropecuaria están determinados por factores tales como las condiciones de fertilidad de los suelos, acceso al agua o clima. Pero por otro lado dependen de los mercados internacionales ya que éstos determinan la demanda y los precios.

En esas condiciones globales, en la actual pandemia se observa una caída sustancial en los precios de los alimentos desde inicios de 2020 alcanzando el peor registro en mayo, para luego recuperarse paulatinamente. El índice de precios de FAO, de base 100, comenzó 2020 en 102.5 para caer a 91 en mayo, y luego recuperarse poco a poco hasta alcanzar 96.1 en agosto. ${ }^{4}$

En los cereales existió una caída seguida por una recuperación alcanzando 102, lo que es un nivel muy cercano al inicio del año (103.8). Los aceites vegetales cayeron fuertemente desde 108.7 en enero a 77.8 en mayo para después recuperarse a 98.7 en agosto. El valor de la soya, alcanzó mínimos en el orden de US\$360 / ton métrica, pero comenzó a elevarse desde julio,

\footnotetext{
${ }^{4} \mathrm{El}$ índice de precios de alimentos de FAO se basa en promedios de cinco commodities vinculados a la participación promedio en el comercio internacional para los años 2014-16; véase http://www.fao.org/worldfoodsituation/foodpricesindex/en/. Más informaciones en: http://www.fao.org/3/ca9509en/ca9509en.pdf
} 
para superar los US\$ 400 / ton m en noviembre, lo que eran precios que no se observaban desde 2018. En cuando a la ganadería, en las carnes la caída es menor pero no ha existido una recuperación, llegando a 93.2 en agosto, mientras que los lácteos se redujeron al inicio de la pandemia, aunque se recuperaron, y llegan a 102.

Como puede observarse, se ha registrado una caída en muchos rubros agropecuarios y recuperaciones en algunos de ellos. Más allá de esos vaivenes queda en evidencia una importante volatilidad en los precios. Así, por ejemplo, el precio por tonelada de cacao estuvo en febrero de 2020 en US\$ 2 900, un mes después había caído a US\$ 2 200; a inicios de septiembre se había recuperado a US\$ 2600 , para volver a caer en octubre a US\$2 $340^{5}$.

Se superponen los problemas claramente originados por la pandemia junto a otros que ya existían. Entre los primeros se cuentan algunos como la contracción en la demanda de algunos alimentos o dificultades en las cadenas de comercialización y exportación. Entre los segundos se cuentan las disputas en el comercio exterior, tales como las que enfrentan a Estados Unidos y China, lo que repercute directamente en las exportaciones agroalimentarias latinoamericanas. También hay problemas sanitarios tanto en cultivos como en cría animal, como son la diseminación de la roya de la soya (producida por hongos) o las influenzas o gripes en aves de cría o en cerdos, como es la reciente epidemia de gripe porcina en China. Se deben sumar, a su vez, las condiciones climáticas, como los extremos de sequías o reducciones en la disposición de agua a las inundaciones, las que afectan directamente las prácticas agropecuarias. Este listado, que es esquemático, busca dejar en claro la superposición de factores que inciden sobre estos sectores extractivos, explicando la relevancia que tienen la volatilidad en los precios y en la demanda.

\section{Principales tendencias en los extractivismos agropecuarios sudamericanos}

Los distintos factores que inciden en los extractivismos agropecuarios se pueden dividir en dos. Por un lado, existan influencias directas que se deben a la caída de los extractivismos basados en minerales e hidrocarburos, por lo que los gobiernos decidieron promover alternativas basadas en la agropecuaria. Por otro lado, como algunos rubros agropecuarios también se derrumbaron, la respuesta fue buscar una alternativa en otro producto también agropecuario. En cualquier caso, la intención era intentar recuperar ingresos por exportaciones.

Ecuador ilustra estas dinámicas. Durante los primeros meses de la pandemia, ese país sufrió una caída drástica de sus ventas de petróleo, un rubro extractivista que es su más importante exportación. Entre enero y junio, el valor de esas exportaciones cayó un 48,2\% en comparación con el mismo periodo del año anterior ${ }^{6}$. Por un lado, el precio del petróleo de referencia (WTI) se desplomó en abril de 2020, llegando incluso a una cotización negativa (US\$ -37,63 el 20 de abril). Por otro lado, en la red de conectividad ocurrió una rotura en un oleoducto principal (7 de abril de 2020), que impuso una fuerte reducción de la exportación. La administración de Lenin Moreno había calculado su presupuesto para 2020 con un precio promedio de US $\$ 51,3$ / barril, pero en abril la cotización promedio era de US\$14,04 /barril.

\footnotetext{
${ }^{5}$ https://www.ifcmarkets.com/es/market-data/commodities-prices/cocoa

${ }^{6}$ Los datos de esta sección están basados en la Información Estadística Mensual (IEM), Banco Central Ecuador, en https://contenido.bce.fin.ec/home1/estadisticas/bolmensual/IEMensual.jsp
} 
A la caída del petróleo se sumaron reducciones en otros productos no tradicionales de exportación ecuatorianos, especialmente flores y enlatados de pescado. De este modo, las exportaciones totales del país disminuyeron un 13,6\% entre enero y junio.

Frente a este escenario, la respuesta estatal se centró en sustituir los hidrocarburos por otros productos. Por medio de una campaña publicitaria manejada por el Ministerio de Agricultura se promovió el slogan: "El verdadero petróleo está en el agro". Se apuntó a fomentar rubros de agroexportación, tanto tradicionales (como cacao, banano o camarón), como los no tradicionales, buscando aminorar aquella caída de ingreso de dólares por exportación (figura 1). Con esto se mantiene una lógica extractiva, sin considerar adecuadamente los impactos sociales, territoriales y ambientales.

Esa postura en el corto plazo, y dentro de su marco de racionalidad, puede dar algunos resultados. En Ecuador, en los primeros seis meses de la pandemia, a pesar de las medidas restrictivas y los cierres temporales de fronteras y mercados a nivel global, aumentaron las exportaciones agropecuarias, logrando incluso el valor más alto de los últimos 10 años. El valor de las exportaciones de madera aumentó $202 \%$ (dentro de esta categoría, la madera de balsa aumentó un $318 \%$ ), de cacao $25,5 \%$, de banano $17 \%$ y de camarón $7 \%$, en la comparación de 2020 contra el mismo período de 2019. Mientras tanto, el valor de las exportaciones de enlatados de pescado y de flores se redujo alrededor del $6 \%{ }^{7}$; para la Asociación de Productores y Exportadores de Flores del Ecuador (Expoflores), la situación era más severa (indican una caída en sus ventas del $70 \% \%^{8}$ ).

Figura 1. Exportaciones no petroleras. Millones US\$, entre enero y junio 2020.

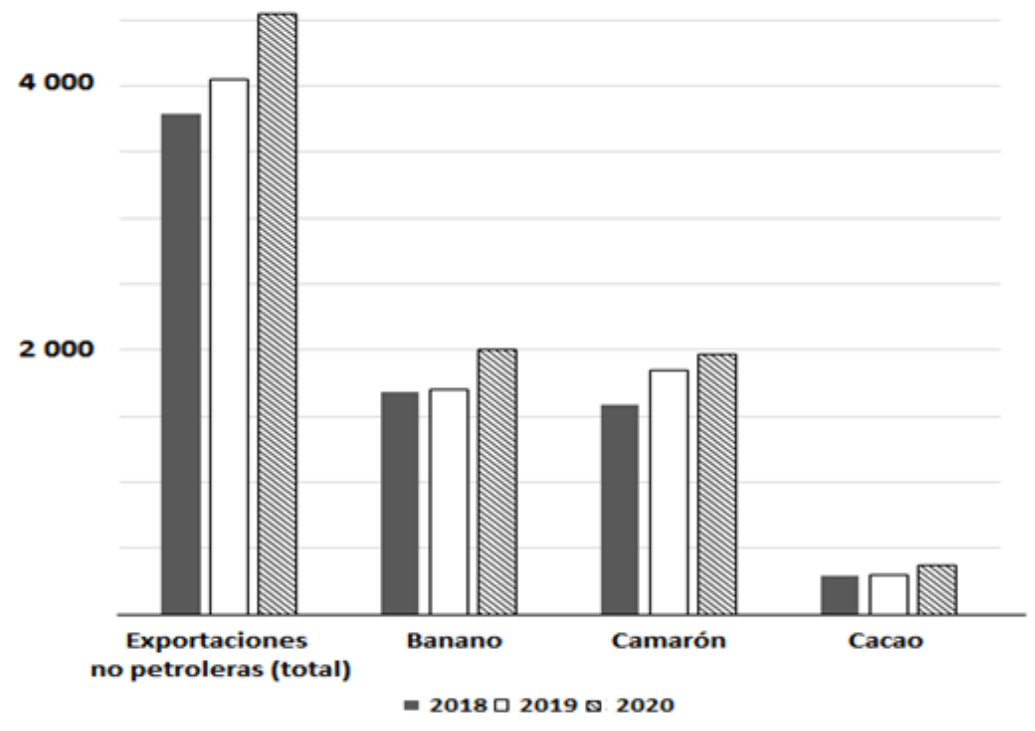

Elaboración propia a partir de datos del boletín de Información Estadística Mensual (IEM), Banco Central del Ecuador 2020.

\footnotetext{
${ }^{7}$ Datos del IEM, Banco Central Ecuador, citado arriba.

${ }^{8} \mathrm{https}$ // www.elcomercio.com/actualidad/ventas-floricolas-ecuatorianas-perdidas-covid.html
} 
En Bolivia, los extractivismos más importantes desde el punto de vista económico, basados en la exportación de gas natural, fueron afectados de variadas maneras. La caída de los precios internacionales tuvo consecuencias directas en los precios y volúmenes exportados a Brasil y Argentina. Al mismo tiempo, ocurrieron controversias sobre los contratos, especialmente con Brasil, argumentando que la pandemia le obligaba a una sustancial reducción de sus compras. Es, por lo tanto, una situación similar a la de Ecuador.

En estas circunstancias el gobierno transitorio de Jeanine Añez decidió sostener e incentivar los extractivismos agrícolas, los que ya venían en expansión desde años atrás (McKay, 2018). Se creó un Fondo de Reactivación Económica (FORE), dotado con US\$1 738 millones, para canalizar créditos a los sectores agrícola entre otros; la medida fue celebrada por el empresariado de la soya ya que permitiría pagar deudas de corto plazo 9 . Se estima que el sector agropecuario es el más beneficiado por ese tipo de medidas, recibiendo aproximadamente US\$ 600 millones $^{10}$.

En otros países se mantienen los extractivismos agropecuarios clásicos, como se registra por ejemplo en Brasil y Uruguay. En Brasil, mientras otros sectores caían, aumentaron los extractivismos agropecuarios hasta convertirse en el principal sostén del comercio exterior. En el primer semestre de 2020, esas exportaciones fueron $10 \%$ más altas que las del mismo período en 2019, lideradas por la soya (exportaron casi 14 mil millones ton, un $61 \%$ más que en 2019) ${ }^{11}$. Mientras que varios sectores de la economía de ese país se derrumbaron con la pandemia, el producto agropecuario aumentó 6,75 \% a julio 2020. Se estima al final del año 2020 un aumento del 14\%, lo que es un record. Por detrás de esos indicadores se observa un incremento de productos clásicos, como los aumentos de exportación como soya, café y carne vacuna y porcina ${ }^{12}$.

La demanda asiática, especialmente desde China, incide directamente en sostener esos extractivismos. Aún en la pandemia, las importaciones agroalimentarias de China aumentaron (Cepal y FAO, 2020b). La pandemia no logró promover una comercialización de agroalimentos dentro de América Latina (13\% de las exportaciones totales), persistiendo las ventas hacia otros continentes $(87 \%$ ) (Cepal y FAO, 2020b).

\section{Permanencias y recambios}

Las condiciones ejemplificadas en la sección anterior indican que están en marcha tanto permanencias como recambios. En efecto, se mantienen varios extractivismos agropecuarios que cuentan con destinos comerciales y precios aceptables. Paralelamente, se intentan recambios sea por extractivismos agropecuarios que suplantan a los mineros o petroleros, o por alternancias entre distintos productos agropecuarios. Estas opciones se combinan de distinto modo.

\footnotetext{
9 ANAPO pide acelerar la implementación de la reactivación productiva. Economy, Santa Cruz, 29 de junio de 2020 , https://www.economy.com.bo/negocios-economy/4162-anapo-pide-acelerar-la-implementacion-de-la-reactivacion-productiva 10 Tierra: Gobierno usa fondos a título de emergencia para pagar deudas del agro. Página Siete, La Paz, 1 julio 2020 , https://www.paginasiete.bo/economia/2020/7/1/tierra-gobierno-usa-fondos-titulo-de-emergencia-para-pagar-deudas-delagro-260044.html

${ }_{11}$ CNA-CEPEA. 2020. PIB do agronegócio avança 1,26 \% em julho. PIB do Agronegócio, CNEA y CEPEA, 8 octubre 2020, https://www.cepea.esalq.usp.br/upload/kceditor/files/Cepea_CNA_Pib_jul_2020.pdf

12 Los ingresos por la agropecuaria crecerán cerca del 14\% este año, récord para Brasil, EFE Brasil, 16 setiembre 2020 , https://www.efe.com/efe/america/economia/los-ingresos-por-la-agropecuaria-creceran-cerca-del-14-este-ano-record-parabrasil/20000011-4344570
} 
En los inicios de la pandemia, las principales medidas apuntaron a garantizar la disponibilidad y acceso a los alimentos en casi todos los países sudamericanos, a apoyos económicos de distinto tipo (en Ecuador, Perú, Chile, Paraguay y Uruguay a inicios de la pandemia), y a no interrumpir las cadenas de transporte (Cepal y FAO, 2020a).

En países como Uruguay, la pandemia no alteró sustancialmente sus estrategias agropecuarias. Continuó con su principal programa de apoyo en ese sector, que estaba representado con el inicio de la construcción de una nueva planta de procesamiento de celulosa (procesará de 2,1 millones ton de pasta de celulosa por año, convirtiéndola en una de las más grandes del mundo), y persiste el cultivo de soya transgénica. Estrategias análogas pueden ser indicadas para Brasil, Colombia o Bolivia.

En otros casos, al observarse la caída de un rubro agropecuario importante se buscó la complementación con otro. En Ecuador ante la dramática reducción en el cultivo y exportaciones de flores, se promovieron otros productos como el cáñamo o el aguacate tipo has, amparados en campañas comunicacionales, talleres informativos y asistencia técnica.

En Argentina existen polémicas ante algunos cambios. El gobierno está promoviendo la ampliación de la cría de cerdos para exportar esa carne a China. Se analiza un acuerdo comercial para sumar 900 mil ton de carne porcina, lo que implica aumentar a casi 10 millones de animales, que requerirán alimentos por más de 2 millones ton de maíz y 750 mil ton soya, lo que a su vez impone un aumento del área cosechada en más de 500 mil has; también necesitarán más de 12 mil millones litros de agua, y se duplicarían las emisiones de gases invernadero de ese sector (FARN, 2020). Ese emprendimiento puede calificarse como un análogo a la megaminería a cielo abierto; dicho de forma esquemática, es un megaextractivismo de animales estabulados. En Uruguay, el Ministerio de Ganadería, Agricultura y Pesca, también está analizando proyectos para exportar carne de cerdo a China ${ }^{13}$.

Otra situación se encuentra en países que parecería que no reaccionan con medidas de apoyo al sector agropecuario. En Perú, donde la pandemia tuvo impactos negativos especialmente en pequeños agricultores, las medidas del Ministerio de Agricultura y Riego (Minagri) han sido limitadas o bien no han existido apoyos focalizados para los más perjudicados ${ }^{14}$. Por ejemplo, el fondo de créditos para pequeños agricultores (FAE Agro) padece de una pobre implementación, aunque por otro lado se ejecutó un masivo programa de apoyo a la minería.

En paralelo a esto, en varios países, se repite que la mayor parte de las medidas estatales favorecen a los grupos agroexportadores, mientras que se relegan aquellas para campesinos y los agricultores pequeños o familiares. Esto tiene implicancias severas en el contexto de la pandemia, ya que esa pequeña agricultura es mucho más diversificada y en varios sitios es indispensable para producir alimentos que se consumen a nivel local o nacional.

Por ejemplo, en Colombia el gobierno concretó pocas medidas, varias fueron reformulaciones de instrumentos que ya existían ${ }^{15}$, y otras, como brindar beneficios tributarios a las inversiones

\footnotetext{
13 El gobierno evalúa proyecto para un nuevo frigorífico, Telenoche, Montevideo, 17 noviembre 2020 , https://www.telenoche.com.uy/nacionales/gobierno-evalua-proyecto-para-nuevo-frigorifico

${ }^{14}$ Impacto del COVID-19 en la agricultura: sin bono y sin FAE-AGRO, E. Zegarra, Otra Mirada, Lima, 28 octubre 2020 , http://www.otramirada.pe/impactos-del-covid-19-en-la-agricultura-sin-bono-y-sin-fae-agro

15 Las deudas de Minagricultura con los campesinos durante la pandemia, La Liga contra el Silencio, 8 julio 2020 , https://ligacontraelsilencio.com/2020/07/08/las-deudas-de-minagricultura-con-los-campesinos-durante-la-pandemia/
} 
favorecen a las empresas pero tiene poca utilidad para el campesinado ${ }^{16}$. Entretanto, estos padecen crecientes costos, no logran comercializar sus productos, se endeudan, y en algunos casos buscan abandonar el campo.

Esta situación también se observa en Ecuador. Las organizaciones campesinas y de la sociedad civil señalan que aumentaron las dificultades que enfrentan debido a las medidas restrictivas por el Covid19 (FIAN Ecuador et al., 2020). Se avanzó en normas que favorecen actores empresariales, como la Ley de Palma Aceitera, cuyo objetivo es regular las actividades a lo largo de esa cadena de producción, implementar medidas para el mejoramiento de la productividad, regular créditos, entre otras ${ }^{17}$. No existen medidas análogas para la agricultura campesina. Del mismo modo, buscando rescatar las exportaciones de flores, el gobierno concretó un nuevo acuerdo comercial con Estados Unidos, que le brinda un arancel cero, lo que favorece directamente a las empresas exportadoras ${ }^{18}$.

Otras permanencias llamativas están en el mantenimiento de subsidios perversos por ejemplo a agrotóxicos o combustibles fósiles, a pesar del llamado de varias agencias de aprovechar la pandemia para avanzar en esos cambios (Cepal y FAO, 2020b).

El extractivismo bananero en Ecuador como ejemplo

Para ilustrar con más detalle varios de los puntos indicados arriba, se presenta al caso del extractivismo bananero en Ecuador. Recordemos que el banano ha sido uno de los principales rubros extractivistas ecuatorianos, y actualmente es el primer exportador mundial. Representa el segundo producto entre las exportaciones no petroleras, después del camarón. La superficie cultivada superó 190 mil has, y se obtuvieron 6,5 millones ton m en 2019 (INEC, 2020).

Durante los primeros seis meses del 2020, las exportaciones de banano aumentaron tanto en valor como en volumen, como se adelantó arriba. Sin embargo, al mismo tiempo existieron fuertes conflictos, principalmente entre agricultores y exportadores. Debe tenerse presente que la mayoría de los agricultores bananeros tienen menos de 30 hectáreas ${ }^{19}$. Sin embargo, esos pequeños agricultores están desapareciendo mientras que las grandes empresas controlan superficies mayores (Daza et al., 2020). Eso se debe, entre otros factores, a los muy bajos precios que se pagan por el banano dentro del país, volviendo muy dificultoso cubrir los costos del cultivo, llevando en muchos casos al sobreendeudamiento de pequeños productores.

Según Byron Paredes, presidente de la Asociación de Productores Bananeros del Ecuador, los costos de producción por caja están alrededor de US\$ 6; el precio mínimo de sustentación, fijado por la ley, es US\$ 6,40; pero durante los primeros meses de pandemia, los exportadores pagaban aproximadamente US\$ 4 por caja.

\footnotetext{
16 Así funcionarán los beneficios tributarios para las inversiones en el agro, Dinero, Bogotá, 23 junio 2020 , https://www.dinero.com/economia/articulo/cuales-son-los-beneficios-tributarios-para-invertir-en-el-sectoragropecuario/290331

${ }^{17}$ Frente a la aprobación de la ley, en julio 2020, diversas organizaciones de la sociedad civil expresaron su preocupación con una carta pública, pidiendo el veto presidencial debido a los impactos ambientales y sociales de los cultivos de palma aceitera; https://ddhhecuador.org/2020/06/25/documento/carta-abierta-al-presidente-de-la-republica-por-el-veto-la-ley-para-el

${ }_{18} \$ 24$ millones al año en aranceles dejarán de pagar exportaciones de rosas ecuatorianas a Estados Unidos, El Universo, Quito, 1 de noviembre 2020, www.eluniverso.com/noticias/2020/10/31/nota/8033716/rosas-cero-aranceles-exportacion-eeuuacuerdo-comercial-1-noviembre

${ }^{19}$ Según los datos de 2019 del SIPA (Sistema de Información Pública Agropecuaria) en el país existen 7190 productores de banano. De ellos, 5718 tienen menos de 30 hectáreas, y sólo 318 tienen más de 100 hectáreas-
} 
Según lo que plantea la ley de banano ${ }^{20}$, ese mercado está bajo diversas reglamentaciones, tales como la prohibición de ampliar el área cultivada sin la autorización de la Asamblea Nacional, la asignación de un precio mínimo de sustentación, la obligación de vender por medio de un contrato para estabilizar precios para evitar la volatilidad de los mercados internacionales. Las flexibilizaciones en algunos de estos componentes ya fueron adelantadas arriba.

Sin embargo, Byron Paredes afirma que existe una "piratería" de millones de cajas de la fruta que salen del país a nombre de otros productores, sin contar realmente con un contrato y sin acatar el precio controlado. Bajo esas condiciones también se puede suponer que tampoco cuentan con controles ambientales y laborales en sus fincas.

A esto se suma que en el 2019 se plantaron más de 30 mil hectáreas nuevas de banano que no estaban autorizadas, según Paredes, y que estarían en manos de grandes productores ${ }^{21}$. Desde la política pública, en vez de sancionar estos incumplimientos, se avanza en regularizarlos ${ }^{22}$. Se asegura el aumento del volumen comercializado pero también los intereses económicos de los grupos de poder que poseen grandes cantidades de tierra y que controlan la cadena de exportación (Daza et al., 2020; Cajas Guijarro, 2018).

Ese aumento de la oferta interna desencadenó una caída en los precios que estaban dispuestos a pagar las empresas exportadoras y así incumplían el precio mínimo de sustentación. Como reacción, los productores bananeros se movilizaron reclamando precios justos y políticas públicas de control. Eso incluyó expresiones originales, como donar banano a sectores populares en vez de venderlo a los exportadores; se entregaron por lo menos 900 "raciones" de bananos (cada una es suficiente para abastecer una familia). Los agricultores también amenazaron en una suspensión de actividades para aumentar la presión a los exportadores y, sobre todo, al Estado, reclamando medidas en su favor.

Es importante advertir que todo eso permitió cuestionar que se privilegiara el destino exportador del banano frente a las necesidades alimentarias. Pero aún en esas condiciones, no estaba en debate la esencia del extractivismo bananero.

De todos modos, las medidas concretas de la administración Moreno favorecieron sobre todo a las grandes empresas y no sirvieron para apoyar a los agricultores más pequeños. Se persistió en priorizar las exportaciones, asumiendo que ello desencadena efectos positivos que son beneficiosos para todos los actores en la cadena de apropiación, inclusive para las y los pequeños agricultores. Este último extremo es, obviamente, infundado ${ }^{23}$.

Es más, en octubre de 2020 el gobierno fijó el precio mínimo de sustentación de la caja de banano para el siguiente año en un promedio de US\$6,25, que es aún menor al aplicado en el año 2020. Ese valor se corresponde con el solicitado por los exportadores mientras que los agricultores reclamaban ubicarlo en US\$7,05 (según los cálculos de esos agricultores los costos por caja que llegaban a los 5,73 dólares ${ }^{24}$ ). También decidió aplicar un nuevo esquema

\footnotetext{
${ }^{20}$ Ley para estimular y controlar la producción y comercialización del banano, plátano y otras musáceas afines, destinadas a la exportación, 1997, 2004.

${ }^{21}$ Esto explica en parte el aumento de las exportaciones bananeras durante los primeros meses del 2020 a pesar de la pandemia.

${ }^{22}$ Esta regularización se realiza a través del Decreto presidencial №1127 promulgado el 15 de agosto de 2020.

${ }^{23}$ Estos y otros aspectos se analizan en otro estudio enfocado en las exportaciones realizado por una de nosotros (TA) para el Observatorio del Cambio Rural de Ecuador.

${ }^{24}$ Conozca el precio mínimo de sustentación de la caja de banana de Ecuador para el 2021, Vistazo, Quito, 28 de octubre 2020 , www.vistazo.com/seccion/enfoque/conozca-el-precio-minimo-de-sustentacion-de-la-caja-de-banano-de-ecuador-para-el
} 
por el cual se determinan precios distintos para cada época del año (con variaciones desde US $\$ 4,50$ a 6,90). Según los agricultores todo esto aumenta sus vulnerabilidades mientras se favorece a los compradores..$^{25}$

En cambio, los conflictos en marcha evidencian el perjuicio económico para los pequeños agricultores, por lo que algunos caen en sobreendeudamiento e incluso pierden sus tierras. También se deterioran las condiciones de trabajo en las grandes fincas bananeras y aumentan las presiones por incrementar la superficie de cultivo, con lo cual se desplaza la agricultura campesina más diversificada. Paralelamente, éstos y las comunidades locales sufren los impactos ambientales y sanitarios, tales como la falta de controles efectivos de las fumigaciones, las consecuencias que producen los agroquímicos, etc.

Por lo tanto, el caso del banano en Ecuador, muestra que esa actividad no está en discusión sino que persiste y se la apoya. En ello, las políticas públicas profundizan las asimetrías en ese sector, y los conflictos derivan hacia debates sobre los excedentes.

\section{Flexibilizaciones y otros efectos derrame}

En todos los países se observa que para promover las exportaciones se repiten acciones que reducen o flexibilizan las exigencias sanitarias, laborales o ambientales, o los controles en la propiedad o manejo de la tierra. Los gobiernos y las empresas aprovechan la situación de la pandemia y escudándose en la crisis económica y de empleo, presionan por más reducciones en controles sociales y ambientales. Esas condiciones y otras corresponden a los efectos derrame, tal como se definen en Gudynas (2015). Las crisis entrelazadas con la Covid19 han acentuado todavía más varias de ellas.

El concepto de "flexibilización" alude a la reducción de las exigencias normativas, en el control, monitoreo y sanción de regulaciones sociales (incluyendo, entre otras, al empleo, salud, economía, etc.), territoriales (por ejemplo tenencia de la tierra) y ambientales (por ejemplo sobre límites a la contaminación y su fiscalización). La flexibilización puede ser explícita, como sucede con cambios en la normativa, o bien indirecta, como ocurre cuando se deja sin recursos humanos y financieros a las agencias encargadas del control, de la fiscalización o la penalización. Aunque la flexibilización puede ser exigida para favorecer un emprendimiento específico, una vez aprobada se transforma en una rebaja de condiciones para otros emprendimientos y en todo el territorio, y es por ello que constituye un efecto derrame.

En el contexto de la pandemia, se observan varios de esos efectos derrame asociados a los extractivismos agropecuarios. Considerando las llamadas flexibilizaciones laborales, han sido muy evidentes en los extractivismos mineros y petroleros, pero también se están repitiendo en la agricultura y la ganadería. En Ecuador, la Ley de Apoyo Humanitario aprobada en la pandemia permite una mayor explotación de las y los trabajadores rurales, profundizando la precarización de sus condiciones laborales y aumentando las dificultades para reclamar sus derechos frente a los grandes agronegocios. La ley establece "medidas para apoyar la sostenibilidad del empleo", como por ejemplo la posibilidad de un "contrato especial

25 Dos esquemas de precios regirán para la caja de banano en el 2021, El Universo, Quito, 29 de octubre 2020 , www.eluniverso.com/noticias/2020/10/29/nota/8030065/precios-banano-2021-ecuador 
emergente" que permite al empleador reducir de forma unilateral las horas de trabajo del empleado hasta el $50 \%$, con una reducción del salario y de los aportes a la seguridad social ${ }^{26}$.

También operan flexibilizaciones en controles agropecuarios, como pueden ser aquellos agronómicos, veterinarios, etc. Se destaca el aluvión de aprobaciones de nuevas variedades modificadas genéticamente aprovechando las circunstancias de la pandemia. En muchos casos se violan o incumplen aspectos de regulación nacional, o se los modifica para hacerlos viables, y se vuelve imposible la consulta ciudadana por las condiciones sanitarias.

El anterior gobierno boliviano, bajo la presidencia transitoria de Añez, se aprobó la reducción de 40 días a diez días los procedimientos por los cuales el Comité Nacional de Bioseguridad debía encaminar evaluaciones de maíz, caña de azúcar, algodón, trigo y soya, genéticamente $\operatorname{modificados}^{27}$. En Bolivia solo se cuenta con la autorización para la producción de una variedad de soya genéticamente modificada y que representa casi la totalidad del cultivo. Sin embargo, aunque no existe la autorización para el maíz transgénico, es sabido que se lo cultiva y comercializa ${ }^{28}$. El gobierno promovió un instrumento jurídico que permite la convivencia entre las variedades nativas y las modificadas por cualquier tecnología ${ }^{29}$.

En Chile, el gobierno de S. Piñera, desde el Servicio Agrícola y Ganadero, aprovechó las condiciones de las cuarentenas para intentar aprobar una liberalización de variedades transgénicas ${ }^{30}$. Debió suspender la medida al recibir siete mil comentarios, la mayoría negativos.

En Uruguay, el pasado setiembre se aprobaron nuevos eventos transgénicos: tres variedades de maíz, dos de trigo y dos de soya. Las variedades incluyen atributos conocidos, como la tolerancia al herbicida glifosato, y la llegada de una nueva generación de semillas que son tolerantes a otro herbicida, el glufosinato de amonio ${ }^{31}$. El procedimiento se realizó de forma acelerada, a pesar de informes contrarios desde instituciones académicas, la ausencia de participación de la universidad estatal y reparos del Ministerio de Salud Pública.

El caso uruguayo es particularmente relevante por otra cuestión. Este país, al igual que sus vecinos del Cono Sur, cuenta con enormes monocultivos de soya que se exporta a China. Actualmente es brumadora la evidencia de resistencia de las malezas al glifosato que se utilizó durante años en ese extractivismo. Por esta razón, la anterior generación de eventos transgénicos se está volviendo productivamente inviable. Dicho de otro modo, este es un fracaso de esa estrategia que se diseminó en Argentina, Brasil, Paraguay y Uruguay, y después en Bolivia. Además, múltiples organizaciones ciudadanas y académicos habían alertado años atrás sobre la inevitable generación de malezas resistentes.

\footnotetext{
${ }^{26}$ Artículo 19, Ley Orgánica de Apoyo Humanitario para combatir la crisis sanitaria derivada del COVID-19, Asamblea Nacional, Quito.

${ }^{27}$ Esto corresponde a los Decretos Supremos 4232 y 4248 del 7 y 14 de mayo de 2020, respectivamente.

${ }^{28}$ Productores afirman que Bolivia importó maíz transgénico durante 12 años y que hoy se siembra en Santa Cruz y Tarija. El Deber, Santa Cruz, 14 de mayo de 2020, https://eldeber.com.bo/economia/productores-afirman-que-bolivia-importo-maiztransgenico-durante-12-anos-y-que-hoy-se-siembra-en-san_179176

${ }^{29}$ Decreto Supremo 4348 del 22 de septiembre de 2020

${ }^{30}$ SAG busca abrir la puerta a transgénicos en Chile en medio de la crisis económica y sanitaria, OLCA, Santiago, 16 junio 2020 , http://olca.cl/articulo/ nota.php?id=107972

31 Véase la resolución en el portal del Sistema Nacional de Bioseguridad de Uruguay en: http://www.sistemanacionalde bioseguridad.gub.uy/. Un resumen en: El gobierno aprobó cuatro eventos transgénicos de maíz, trigo y soja de forma acelerada, La Diaria, Montevideo, 5 setiembre 2020, https://ladiaria.com.uy/politica/articulo/2020/9/el-gobierno-aprobo-cuatroeventos-transgenicos-de-maiz-trigo-y-soja-de-forma-acelerada/
} 
La respuesta de las corporaciones fue redoblar su apuesta a herbicidas químicos; nada reconocen sobre aquellos que se vuelven inefectivos y en cambio promueven nuevos productos, en este caso el glufosinato de sodio, lo que a su vez requiere nuevos eventos transgénicos. Por lo tanto, se mantiene la estrategia de un cultivo que depende de agroquímicos, con toda su carga de dependencia tecnológica, costo para los agricultores, y riesgos sanitarios y ecológicos.

La situación es mucho más grave de lo que se asume porque implicaría aceptar una repetición que siempre estará destinada al fracaso, donde una vez que las malezas se vuelvan tolerantes a un agroquímico, las empresas buscarán un nuevo herbicida que lo volverán a vender hasta que una vez más las resistencias lo vuelvan inocuo. La repetición de ese ciclo multiplica los riesgos de efectos negativos en la salud y el ambiente. Se está aprovechando la pandemia para blindar esa estrategia a pesar de su fracaso.

No puede olvidarse que el herbicida glifosato fue indicado como cancerígeno para animales, probable cancerígeno para humanos y genotóxico (IARC, 2015). En el mismo sentido, se han sucedido fallos judiciales contra la presentación comercia de ese producto por la corporación Monsanto (ahora controlada por Bayer) en cortes de Estados Unidos.

También se están aprobando variedades tolerantes al herbicida dicamba, un producto que en otros países está en el centro de críticas y acciones judiciales por sus impactos.

Cualquiera de estas situaciones hubiera generado una acalorada discusión pública en varios países por sus implicancias sociales, económicas y ecológicas, pero se ha aprovechado la pandemia para evitarlas.

Como ejemplo de flexibilización administrativa, en Ecuador, la Agencia de Regulación y Control Fito y Zoosanitaria (Agrocalidad), tomó medidas que favorecieron a los grupos agroexportadores, como suspensión temporal de las exigencias de pago para sus servicios con relación a la sanidad animal, sanidad vegetal, inocuidad de alimentos y laboratorios ${ }^{32}$.

En Bolivia, una vez que el Movimiento al Socialismo (MAS) retomó el gobierno, Luis Alberto Arce, tomó una decisión que es una clara señal de la futura orientación de su administración y que corresponde a un efecto derrame político. En efecto, nombró como ministro de ambiente a un alto dirigente de la Confederación Sindical Única de Campesinos de Bolivia, y presidente de la asociación de ganaderos campesinos del departamento de Pando. Se está otorgando el control ambiental a unos de los actores involucrados en la expansión de la frontera agrícola y en los incendios forestales ${ }^{33}$, y que en algunos sitios, también tienen acuerdos o dependen del agronegocio ${ }^{34}$.

En Brasil, el gobierno de Jair Bolsonaro escalonó varias flexibilizaciones. Por ejemplo, estableció autorizaciones automáticas de agroquímicos si en 60 días no existe una evaluación por un mecanismo que involucra a los ministerios de agricultura, salud y ambiente (el plazo

\footnotetext{
32 Agrocalidad suspende por 60 días pago de servicios, El Telégrafo, Quito, 8 abril 2020, https://www.eltelegrafo.com.ec/ noticias/economia/4/agrocalidad-pago-servicios

${ }_{33}$ Segun el informa de la Fundacion Tierra (2019), se han reportado la presencia de varios asentamientos recientes en la región de la Chiquitania.

${ }^{34}$ Recientemente se firmo un acuerdo de cooperacion entre una asociacion de pequeñ $\{$ os productores campesinos y la Camara Agropecuaria del Oriente. La Jornada, La Paz, 16 de noviembre de 2020, https://jornada.com.bo/cao-y-cioec-bolivia-firmanacuerdo-para-el-desarrollo-del-sector-productivo/
} 
anterior era de 120 días) ${ }^{35}$. A su vez, el clima político instalado por esa presidencia permite que los legisladores representantes de los intereses de ruralistas y agronegocios (conocido como "bancada ruralista") presionen abiertamente por medidas antes impensables, como la liberación del agrotóxico paraquat ${ }^{36}$. Aprobó al menos 315 nuevos agroquímicos a setiembre 2020, entre ellos varios considerados tóxicos por organizaciones ciudadanas, algunos prohibidos en otros países ${ }^{37}$.

También ocurren efectos derrames que involucran flexibilizaciones sobre propiedad, acceso, uso y otras formas de regulación de la tierra. En Bolivia, diversas organizaciones e instituciones, entienden que los incendios forestales ocurren en el contexto de un marco normativo que permite esas prácticas y a la vez beneficia a los actores agroempresariales. Los incendios de bosques en 2019 afectaron más de 5 millones de hectáreas, principalmente en los departamentos de Santa Cruz y Beni, lo que motivó distintos reclamos normativos y cuestionamientos a esas normas (Tierra, 2019).

Desde 2001, cuando se aprueban los términos para deforestar predios privados en el departamento de Santa Cruz, se ha generado un entramado jurídico, logístico, político y técnico que, por ejemplo, ha normalizado la deforestación ilegal y ha aumentado las zonas de influencia de los permisos de quema. Una de las normas más cuestionadas fue promulgada en la gestión de Evo Morales en 2019, sumando otro departamento (Beni) en el esquema de desmontes aprobado en 2001, y ampliándola a propiedades comunitarias ${ }^{38}$.

Los incendios del año 2020, que afectaron nuevamente al oriente boliviano, generaron múltiples críticas al gobierno. La presidente Añez, que en ese momento también era candidata, derogó el decreto de 2019 como parte de sus cuestionamientos a la gestión Morales. Pero lo reemplazó por una nueva norma que es casi idéntica ${ }^{39}$, y repite los componentes favorables al sector agroganadero ${ }^{40}$.

En cuanto a las flexibilizaciones ambientales, se ha aprovechado la pandemia para imponer recortes en los controles, o reducción de los recursos humanos y financieros en las autoridades ambientales. Por ejemplo, el Ministerio de Ambiente de Ecuador sufrió recortes importantes, fueron desvinculados casi 400 funcionarios, y se reducen las capacidades para las tareas de conservación de la naturaleza ${ }^{41}$.

En Argentina, en el plan de expansión de la ganadería de cerdos para exportar a China, indicado arriba, no se contemplan evaluaciones de riesgo ambiental, participación ciudadana o de las comunidades locales, análisis de los riesgos sobre el agua, etc. (FARN, 2020).

\footnotetext{
${ }^{35}$ Governo encurta prazo para aprovar agrotóxicos e provoca desconfiança até no setor agrícola, D. Magri, El País Brasil, 29 marzo 2020, https://brasil.elpais.com/ciencia/2020-02-29/governo-encurta-prazo-para-aprovar-agrotoxicos-e-provocadesconfianca-ate-no-setor-agricola.html

${ }^{36}$ Veja como estes líderes ruralistas pressionaram por liberação de agrotóxico banido, Contra os Agrotóxicos, 22 julio 2020 , https:// contraosagrotoxicos.org/veja-como-estes-lideres-ruralistas-pressionaram-por-liberacao-de-agrotoxico-banido/

37 Governo Bolsonaro aprova mais 31 agrotóxicos para uso dos agricultores, L. Fragão, 23 setiembre 2020 , https://www.portalveg.com.br/noticias/meio-ambiente/governo-bolsonaro-aprova-mais-31-agrotoxicos-para-uso-dosagricultores/

${ }^{38}$ Decreto Supremo 3973 de julio de 2019, el cual modifica el artículo 5 del Decreto Supremo 26075 de febrero de 2001.

${ }^{39}$ Decreto Supremo 4334.

40 CEDIB: el gobierno cambió un decreto incendiario por otro, Pagina Siete, La Paz, 19 de septiembre 2020 , https://www.paginasiete.bo/economia/2020/9/19/cedib-el-gobierno-cambio-un-decreto-incendiario-por-otro-268606.html

${ }^{41}$ Ministerio de Ambiente de Ecuador desvincula a 398 funcionarios por proceso de fusión con Secretaría del Agua y 'optimización' de recursos, El Universo, Guayaquil, 1 octubre 2020, https://www.eluniverso.com/ noticias/2020/ 10/01/nota/7997980/ministerio-ambiente-agua-398-despidos-trabajadores-ecuador
} 
En Brasil, la administración Bolsonaro ha avanzado concertadamente en varios frentes: desfinanciamiento de las agencias de control y evaluación ambiental, reducción del presupuesto para controlar la deforestación, caída en el personal disponible, y liberalización de las exigencias ambientales ${ }^{42}$. Esto ocurrió enmarcado en discursos de rechazo a medidas sociales y ambientales.

Bajo la pandemia, también se reforzaron los efectos derrame que limitan la participación y consulta ciudadana, y el acceso a la información. Esto es evidente en las propuestas de liberar transgénicos comentadas arriba. Otro ejemplo es la desatención a las observaciones vecinales por posibles impactos de la infraestructura ferroviaria de la nueva planta de celulosa en Uruguay ${ }^{43}$. De modo análogo, en Argentina se ha denunciado que se han anulado audiencias públicas para evaluar permisos de deforestación, como ocurrió en la provincia de Salta ${ }^{44}$.

A su vez, persisten las protestas de distintos grupos y organizaciones de la sociedad civil ante los extractivismos agropecuarios, y se aprovecha la pandemia para controlarlos, como sucede en Perú.

Finalmente, un ejemplo de la articulación entre varios efectos derrame corresponde a los incendios forestales en América del Sur en tanto están directamente asociados a los extractivismos agropecuarios. Bajo la actual pandemia se repitieron los incendios. La atención está enfocada en Brasil, con más de 200 mil focos de calor a fines de octubre 202045 . En ese país, un 46\% se ubicaron en la Amazonia, y son los que publicitados por los medios. Pero afectaron también a la ecoregión del Cerrado (29\%), donde predominan la ganadería y la soya, y en el humedal del Pantanal (10\%). Pero este problema repite en otros países, como Argentina (más de 70 mil focos de calor), con severos impactos en áreas sobre el curso del Río Paraná, seguidos por Venezuela (más de 35 mil focos), Bolivia (casi 35 mil focos en el bosque chiquitano y otros ecosistemas) y Paraguay (más de 34 mil focos por ejemplo en el Chaco). Del total de focos registrados en América del Sur, el 48\% ocurren en Brasil, seguido por Argentina con casi el 17\%.

Casi todos esos incendios ocurren en áreas bajo presión agrícola ganadera, sea por prácticas intencionales de quema estacional para liberar zonas de pastura o deforestadas, o por fuegos accidentales o intencionales de apertura sobre nuevos sitios. Las condiciones de sequía que existen en 2020 en regiones subtropicales sudamericanas aumentaron su incidencia en algunos ecosistemas, como el Pantanal. Esta problemática se repite desde hace años, y es justamente esa reiteración que deja en claro los efectos derrame ya que no se han logrado resolver.

\footnotetext{
42 Apesar de incêndios, governo corta orçamento do Ibama e ICMBio em 2021, Folha de São Paulo, 13 setiembre 2020, https://www1.folha.uol.com.br/ambiente/2020/09/apesar-de-incendios-governo-corta-orcamento-do-ibama-e-icmbio-em2021.shtml.

Em dez anos, Ibama perde 55\% dos fiscais para combate a crimes ambientais, A. Borges, Estado São Paulo, 14 agosto 2020 , https://noticias.uol.com.br/meio-ambiente/ultimas-noticias/ag-estado/2020/08/14/em-dez-anos-ibama-perde-55-dosfiscais-para-combate-a-crimes-ambientais.htm

Brasil corta recursos para combater o desmatamento, 3 junio 2020, Diário do Comércio, Belo Horizonte, https://diariodocomercio.com.br/dc-mais/brasil-corta-recursos-para-combater-o-desmatamento

${ }^{43}$ El Proyecto de UPM avanza a pesar de imprevisiones e incumplimientos, V.L. Bacchetta, Sudestada, Montevideo, 18 Octubre 2020, https://www.sudestada.com.uy/articleId_1f786750-ff40-49ee-910a-608fa120c632/10893/Detalle-de-Noticia

${ }^{44}$ La Provincia quitó las audiencias públicas para tala y desmontes selectivos, L. Urbano, Página 12, Salta, 20 octubre 2020 , https://www.pagina12.com.ar/300392-la-provincia-quito-las-audiencias-publicas-para-tala-y-desmo

45 Informaciones basadas en el Programa Queimadas, Instituto Nacional de Pesquisas Espacias (INPE), Brasil, en http://queimadas.dgi.inpe.br/queimadas/portal-static/situacao-atual/
} 
En Bolivia, donde se ha analizado en detalle está situación, se encuentra una relación directa con los extractivismos agropecuarios. Entre los años 1985 y 2018 se han perdido 3,6 millones de hectáreas de bosque, que se convirtieron en tierras agropecuarias (Vos et al., 2020). En ese proceso, existe evidencia que los incendios promueven el avance de la frontera agropecuaria; se estiman que, de los 6,4 millones de hectáreas quemadas en 2019, el 84\% estaría relacionada usos agrícola ganaderos (Vos et al., 2020; véase además Campanini et al., 2020).

En Brasil, a pesar de la gravedad de los incendios de 2019, las medidas implementadas no lograron evitarlos en 2020. Los discursos del presidente Jair Bolsonaro y varios de sus aliados alientan la impunidad, a la vez que responsabiliza a indígenas y pequeños agricultores por esas quemas. Sin embargo, en la Amazonia brasileña, la mayor parte de los incendios (72\%) ocurrieron en predios medios y grandes (más de 400 has), lo que permite rechazar la validez de esas afirmaciones de Bolsonaro (Alencar et al., 2020). Además, aunque su gobierno militarizó el control de la Amazonia y el combate a los incendios como resultado de la crisis de 2019, la situación registrada en 2020 deja en claro la inefectividad de esa medida ${ }^{46}$.

\section{Discusión y conclusiones}

La revisión presentada en este artículo, aunque preliminar y bajo condiciones rápidamente cambiantes propias de la pandemia, muestra que la respuesta generalizada desde los gobiernos ha sido mantener los extractivismos agropecuarios en todos sus tipos. En unos casos, se los defiende como alternativa a las caídas exportadoras de extractivismos mineros o petroleros, y en otros casos se los defiende en sí mismos alternando entre distintos productos.

Se han utilizado argumentos y legitimaciones referidas a la pandemia para reforzarlos desde el Estado, y esas posiciones cuentan con el respaldo de casi todos los agrupamientos políticos partidarios, actores empresariales, y buena parte de la academia. Por lo tanto, persisten todos sus impactos sociales, territoriales y ambientales; no es posible hablar de una pausa o reducción en esos efectos.

Los cambios observados están directamente vinculados con las condiciones externas. Los balances en precios internacionales, demanda y acceso a mercados de destino determinan cuáles productos son abandonados y cuáles se expanden. Esto confirma la importancia de la articulación glocal de los extractivismos, ya que, aunque dependen de recursos naturales ubicados en sitios específicos son comercializados en cadenas globales. Esas condiciones internacionales son mucho más determinantes en el desempeño de esos sectores y los gobiernos mantienen un papel secundario. Por lo tanto, están inmersas en un capitalismo agropecuario internacionalizado (véase por ejemplo Alonso-Fradejas, 2019).

En esas condiciones internacionales sigue avanzando la relevancia de China, especialmente como comprador de agroalimentos, lo que a su vez alimenta las presiones extractivistas. Al mismo tiempo, como los procesos de integración latinoamericanos, como Unasur o CELAC, están prácticamente desmontados, se debilitaron todavía más las capacidades de los países de lidiar con los condicionamientos globales. Esta problemática se repite con los países que negocian acuerdos de libre comercio (como el Mercosur con la Unión Europea).

46 Queimadas em agosto confirman que Exército fracassou na Amazônia, Observatório do Clima, 1 septiembre 2020 , http://www.observatoriodoclima.eco.br/queimadas-em-agosto-confirmam-que-exercito-fracassou-na-amazonia/ 


\section{Extractivismos agropecuarios en tiempos de pandemia}

En algunos países y en algunos rubros, las exportaciones agroalimentarias se mantuvieron y por lo tanto se volvieron muy importantes en un contexto de caída en otros rubros exportados. En América Latina y el Caribe, se registró una caída de las exportaciones totales durante los primeros meses de pandemia, pero aquellas agroalimentarias al resto del mundo aumentaron un $6,8 \%$ con respecto al año anterior, y dentro del continente cayeron un - $0,8 \%$ (Cepal y FAO, 2020b). La demanda China fue clave en esa dinámica.

La pandemia no fue utilizada para revertir las estrategias de convertir alimentos en commodities de exportación. La urgencia por los recursos económicos hace que, al favorecerse sectores orientados a la exportación, se refuerza el papel de una ganadería y agricultura volcada a producir mercaderías para exportar en vez de proveer alimentos para sus propios habitantes. La crisis sanitaria hace más evidente las contradicciones en esas estrategias.

En varios países es evidente la necesidad de reforzar el componente alimentario en la lucha contra la pobreza. Por ejemplo, en Bolivia, Ecuador o Perú, se podría lograr un auto abastecimiento de alimentos de toda la población para anular de ese modo el déficit nutricional entre los más pobres. Sin embargo, las posturas gubernamentales privilegian los intereses empresariales que se enfocan en las exportaciones asumiendo que eso les asegura una rentabilidad más alta.

Las medidas gubernamentales benefician sobre todo a actores empresariales y corporativos, y una vez más se relegan A pequeños agricultores o campesinos, y a los trabajadores rurales. Esto se debe tanto a esa expectativa de mayor rentabilidad con las exportaciones que se acaba de señalar, como a las desigualdades estructurales que son previas a la actual pandemia. Son asimetrías, entre otras, en el acceso a recursos productivos, la tierra, el capital y el poder político, y que siempre han favorecido a los actores empresariales. Los agricultores pequeños o familiares, campesinos o indígenas son relegados. Pero a la vez, éstos últimos deben lidiar con crecientes costos, sufren más perjuicios (económicos, sociales, sanitarios o ambientales), y se reproducen sus condiciones de vulnerabilidad y precarización.

El hecho clave es que la pandemia no fue usada por ningún gobierno para intentar una modificación de esas asimetrías, para potenciar la agropecuaria interna de manera de reducir la dependencia exportadora, ni tampoco para reducir los perjuicios que padecen los agricultores más pequeños o campesinos.

Del mismo modo, la pandemia no ha servido para frenar los efectos derrame de los extractivismos, $y$, por el contrario, varios de ellos se han acentuado. Los más evidentes son las medidas de flexibilizaciones en las condiciones sanitarias, laborales y ambientales. Parecería que se aprovecha que, en esta crisis, los actores clave en la política, los medios e incluso la academia, están enfocados en los impactos sanitarios y la problemática social más evidente, como desempleo y pobreza. Entonces se insiste en que la solución a esas cuestiones necesariamente requieren recuperar el crecimiento económico, y por lo tanto se deben aprovechar todos los extractivismos. Bajo esas condiciones, las flexibilizaciones no son interpretadas como un retroceso o como origen de conflictos, sino que para muchos son bienvenidas como posible solución económica.

La pandemia también favorece un creciente autoritarismo y con ello los retrocesos en acceso a la información, participación y resolución de conflictos. Esto hace que muchos extractivismos agropecuarios enfrenten una oposición más debilitada. Se están fortaleciendo efectos derrame que operaban desde antes, que no sólo limitan la participación ciudadana, 
sino que además naturalizan la violencia en los extractivismos (véase por ejemplo, Ojeda y Berman-Arévalo, 2020 en Colombia, y Campanini et al., 2020 en Bolivia).

Es más, podría argumentarse que se está generando un retroceso en algunos frentes. Por ejemplo, las advertencias sobre los monocultivos y los transgénicos, las consecuencias de los agroquímicos o la marcha de la deforestación, parecerían recibir todavía menos atención en varios países, y las organizaciones ciudadanas encuentran más obstáculos para poder enfrentar esas consecuencias.

Sin embargo, son muy comunes los debates sobre los extractivismos en general, y sobre aquellos agropecuarios también. Pero esas discusiones no están centradas en las alternativas para salir de la dependencia extractivista, sino que expresan oposiciones entre quienes desean asegurarse ventajas, usualmente económicas, y lo que buscan evitar perjuicios, muchas veces sociales y ambientales.

Las expresiones más visibles son los reclamos por subsidios, medidas para aumentar la captación de renta, reclamos de flexibilidades sociales y ambientales, etc. Ante ellas están los que rechazan padecer las externalizaciones de los impactos sociales, ambientales y económicos. Todo eso corresponde a discusiones sobre el manejo de excedentes, entendidos en un sentido ampliado que incluye componentes tanto monetarizados (por ejemplo, ganancia o plusvalía) como no monetarizados (tales como afectaciones en la fertilidad del suelo o la calidad del agua), en el sentido de Gudynas (2020).

Disputas como las analizadas para el banano ecuatoriano muestran esa dinámica. En ellas, la esencia del extractivismo agrícola no está en cuestión, sino que son enfrentamientos entre las ventajas que se desean capturar y los perjuicios que se intentan evitar, desplegados entre actores privados, como empresas y pequeños agricultores, aunque también en ocasiones el Estado puede intervenir si desea capturar parte de ese excedente, como sucede con los impuestos a las exportaciones de granos en Argentina. Pero los debates sobre los excedentes no sólo aceptan los extractivismos, sino que los necesitan, requieren que produzcan excedentes económicos, y para que eso sea posible es inevitable mantener externalidades sociales y ambientales. Distintos efectos derrame legitiman esas batallas por los excedentes a la vez que se inhiben o bloquean las opciones para salir de esos extractivismos.

Por estos modos se mantienen los aspectos esenciales de los extractivismos agropecuarios, que pueden caracterizarse, siguiendo a McKay (2018), como la extracción del valor ecológico desde tierras fértiles mientras las utilidades económicas generadas son apropiadas en otros sitios del planeta. De todos modos, siempre debe tenerse presente que hay diferencias importantes entre estos extractivismos y aquellos basados en minerales o hidrocarburos, tanto por ser recursos renovables como por la diferente organización social y económica (Reboratti, 2017 acertadamente señala algunas distinciones).

Los efectos derrame con crecientes restricciones ciudadanas y autoritarismo ya estaban en marcha en años anteriores, pero la pandemia los ha acentuado. Entre los casos extremos se cuentan los gobiernos de Brasil y Colombia, pero también debe tenerse presente las crisis políticas que se sufren desde 2019 en Chile, Ecuador, Perú y Bolivia.

Los efectos derrame son una de las consecuencias más serias de los extractivismos, e incluso más graves que sus impactos locales, al comprometer aspectos básicos en las políticas públicas 
y la calidad democrática. La presente revisión indica que en los extractivismos agropecuarios se repite esa problemática.

De ese modo, el avance de la pandemia de Covid19 fueron aprovechadas para aplicar controles y restricciones, confinamientos, cuarentenas, etc., en varias ocasiones respaldados con fuerzas policiales y militares. Todo ello es funcional a mantener y reproducir los extractivismos, limita las capacidades de las organizaciones ciudadanas para enfrentarlos, y bloquea las posibilidades para imaginar y ensayar alternativas postextractivistas.

\section{Referencias}

Alencar, A., Rodrigues, L. y Castro, I. (2020) Amazônia em chamas: o que queima - e onde. Nota Técnica, IPAM, 5: 1-14.

Alonso-Fradejas, A. (2019) El proyecto de capitalismo agroextractivo: una mirada a la cuestión agraria contemporánea desde Guatemala, En Rubio, B. (ed.) América Latina en la mirada: las transformaciones rurales en la transición capitalista. México: Instituto de Investigaciones Sociales, UNAM.

Cajas Guijarro, J. (2018) Los capos del comercio. Concentración, poder y acuerdos comerciales en el Ecuador: un preludio. Quito: Plataforma por el Derecho a la Salud, Fundación Donum y FOS.

Campanini, O., Gandarillas, M. y Gudynas, E. (2020) Derechos y violencias en los extractivismos. Extrahecciones en Bolivia y Latinoamérica. Cochabamba: La Libre.

Cepal y FAO (2020a) Análisis y respuestas de América Latina y el Caribe ante los efectos del COVID-19 en los sistemas alimentarios. Boletín 2, CEPAL - FAO: 1-17.

Cepal y FAO (2020b) Sistemas alimentarios y COVID-19 en América Latina y el Caribe: Comportamiento del comercio durante la crisis. Boletín 12, CEPAL - FAO: 1-16.

Daza, E., Chuquimarca, I., Singaña, D., Artacker, T. y Llerena, M.J. (2020) Comercio justo. Estudio de impactos del Tratado de Libre Comercio entre la UE y Ecuador en la agricultura. Berlín: F. Ebert Stiftung.

FARN (2020) ¿Cerdos para China made in Argentina? Acerca del posible acuerdo de producción y exportación de carne porcina a la República Popular de China. Buenos Aires: Fundación Ambiente y Recursos Naturales (FARN).

Fernandes, B.M. (2019) Land grabbing for agro-extractivism in the second neoliberal phase in Brazil. Nera 22 (50): 208-238.

FIAN Ecuador, Instituto Estudios Ecuatorianos, Observatorio del Cambio Rural, Unión Tierra y Vida y FIAN Internacional (2020) La pandemia y los derechos de los campesinos en Ecuador. Informe Mayo 2020. Quito: FIAN Ecuador, Instituto Estudios Ecuatorianos, Observatorio del Cambio Rural, Unión Tierra y Vida y FIAN Internacional.

Grecchi, R.C., Gwyn, Q.H.J., Bertin Bénié, G., Formaggio, A.R., y Fahl, F.C. (2014) Land use and land cover changes in the Brazilian Cerrado: A multidisciplinary approach to assess the impacts of agricultural expansion. Applied Geography 55: 300-312.

Gudynas, E. (2010) Agropecuaria y Nuevo extractivismo bajo los gobiernos progresistas de América del Sur. Territorios, CONGCOOP 5: 37-54.

Gudynas, E. (2015) Extractivismos. Ecología, economía y política de un modo de entender el desarrollo y la Naturaleza. Cochabamba: CEDIB.

Gudynas, E. (2020) Excedente en el desarrollo: revisión y nueva conceptualización desde los extractivismos. Estudios Críticos Desarrollo, México, 9 (17): 25-56.

IARC. (2015) Some organophosphate insecticides and herbicides. IARC Monographs 112.

INEC (2020). Encuesta de superficie y producción agropecuaria continua. Quito: Instituto Nacional de Estadística y Censos y ESPAC.

Infante-Amate, J., Urrego Mesa, A. y Tello Aragay, E. (2020) Las venas abiertas de América Latina en la era del antropoceno: un estudio biofísico del comercio exterior (1900-2016). Diálogos, Revista electrónica Historia 21 (2): 177-214.

McKay, B. (2018) Extractivismo agrario. Dinámicas de poder, acumulación y exclusión en Bolivia. La Paz: Fundación Tierra. 
Ojeda, D. y Berman-Arévalo, E. (2020) Ordinary geographies: care, violence, and agrarian extractivism in "post-conflict" Colombia. Antipode 52 (6): 1583-1602.

Reboratti, C. (2017) Agricultura y extractivismo. Voces en el Fénix 8 (60): 118-125

Tierra. (2019) Fuego en Santa Cruz: balance de los incendios forestales 2019 y su relación con la tenencia de la tierra. La Paz: Informe Especial, Fundación Tierra.

Travela, J.C. (2020) Aportes para la construcción de una hegemonía postextractivista: Análisis con énfasis desde los agronegocios en Argentina. Revista Iberoamericana Economía Ecológica 32 (1): 120-130.

Vos, V., Gallegos, S., Czaplicki-Cabezas, S. y Peralta-Rivero, C. (2020) Biodiversidad en Bolivia: Impactos e implicaciones de la apuesta por el agronegocio. Revista Mundos Rurales, CIPCA 15: 26-35 